\title{
COMPARATIVE STUDIES ON THE REPRODUCTIVE SYSTEM OF ELYSIA BANGTAWAENSIS SWENNEN, 1998, ELYSIA LEUCOLEGNOTE JENSEN, 1990, AND ELYSIA SINGAPORENSIS SWENNEN, 2011 (GASTROPODA: SACOGLOSSA: PLAKOBRANCHIDAE)
}

\author{
Pattanasuda Sirinupong ${ }^{1 a^{*}}$ and Somsak Buatip ${ }^{2 a}$ \\ aBiology Division, Department of Science, Faculty of Science and Technology, Prince of Songkla \\ University, Pattani campus 94000, THAILAND. Email: pattanasuda.c@psu.ac.th ${ }^{1}$; somsak.bu@psu.ac.th ${ }^{2}$ \\ *Corresponding author: pattanasuda.c@psu.ac.th \\ Received: 22 $2^{\text {nd }}$ May $2017 \quad$ Accepted: $24^{\text {th }}$ Jan 2020 \\ Published: $29^{\text {th }}$ Feb 2020
}

DOI: https://doi.org/10.22452/mjs.vol39no1.4

\begin{abstract}
Reproductive systems of three sacoglossan species, Elysia bangtawaensis Swennen, 1998, E. leucolegnote Jensen, 1990, and E. singaporensis Swennen, 2011, were analyzed using light microscopy, scanning electron microscopy, whole mount technique and a stereomicroscope in order to investigate its reproductive system. Elysia bangtawaensis and E. leucolegnote were collected from a waterway in the tidal area of the mangrove forest around Pattani Bay, Thailand, and E. singaporensis was collected from old mangrove forest bordering east side of Sungai Buloh Wetland Park, Singapore. The differences and similarities of reproductive system among three species are: 1) Elysia bangtawaensis and E. leucolegnote have separate male and female follicles, but in E. singaporensis, the follicles were not separated; 2) penis in all three species has conical shape without a stylet but minor morphological differences were found; 3) all species have triaulic reproductive systems including a vaginal duct, a vas deferens and an oviduct; 4) absence of seminal receptacle, genital receptacle and ampulla in $E$. bangtawaensis unlike that in other two Elysia species in which which genital receptacle and ampulla are found. There is one ampulla on each side of E. leucolegnote, and four on each side of $E$. singaporensis. This information of the reproductive systems of the three species can serve as the basis for future comparative studies with other Plakobranchacea.
\end{abstract}

Keywords: Elysia bangtawaensis, E. leucolegnote, E. singaporensis, reproductive system, Sacoglossa

\section{INTRODUCTION}

Plakobranchid sea slugs are gastropods in the Order Sacoglossa of the Subclass Heterobranchia, which vary considerably in forms, and sizes (Schrödl et al., 2011). These sea slugs inhabit various coastal habitats such as muddy beaches, mangrove forests, coral reefs, sea grass meadows, and among seaweeds. The anatomy, especially of the reproductive systems, has been studied in several species. Examples are Elysia maoria by Reid (1964), E. chlorotica and E. cauze by Marcus (1980), E. flava by Thompson \& Jaklin (1988), and E. maoria, E. chilkensis, and E. timida by Jensen (1992). Studies on reproductive systems are fundamental 
for understanding their mechanism of producing offspring.

In Thailand, many species of genus Elysia can be found, especially, $E$. leucolegnote Jensen, 1990, and $E$. bangtawaensis Swennen, 1998. The first report on the reproductive system of $E$. leucolegnote, was described by Jensen (1990). Elysia bangtawaensis and E. siamensis were first described from specimens found respectively in Nong Chick and Yaring districts in Pattani province of Thailand by Swennen (1998) who described parts of the anatomy of both species in detail. More recently, a new species, E. singaporensis from Singapore was described by Swennen (2011). Swennen (2011) also described the anatomy and morphology of $E$. singaporensis in detail. More recently, Jensen (2015) reported on the anatomy of reproductive system in a few Elysia species, E. timida Risso, 1818, E. bangtawaensis Swennen, 1998, and E. ornata Swainson, 1840, collected from the northern coasts of Singapore.

The role and importance of sea slugs in the ecosystem should not be underestimated. They are primary consumers in the food chain (Kieckbusch et al., 2004), and therefore a significant indicator of ecological richness.

This study is focused on the gross anatomy, morphology, histology, and ultrastructure of the reproductive system of Elysia bangtawaensis, E. leucolegnote, and E. singaporensis by utilizing light microscopy and scanning electron microscopy techniques. Apart from the histological study on E. asbecki by Wägele et al. (2010), and the report of rather complex reproductive system of sacoglossans in consisting of many short ducts by Hadfield \& Switzer-Dunlap
(1984), there is little information on the histology of the reproductive system of genus Elysia, especially detailed information about the whole reproductive system. The study of $E$. bangtawaensis, E. leucolegnote and E. singaporensis is therefore significant as there has never been a report of detailed analysis of the reproductive system of these species. Hopefully, the results will serve as a guideline for future comparative studies with other congeneric and confamilial species.

\section{MATERIALS AND METHODS}

\subsection{Gross anatomy}

10 adult specimens of each species were collected, using a pair of forceps. Elysia bangtawaensis and E. leucolegnote were collected from a waterway in a tidal area of a mangrove forest around Pattani Bay, Thailand $\left(06^{\circ}\right.$ $53^{\prime} \mathrm{N}, 101^{\circ} \mathrm{E}$ ) (Figs. $1 \mathrm{~A}, \mathrm{~B}, 2$ ), and $E$. singaporensis was collected from Singapore, Western Johor Straits, in an old mangrove forest bordering east side of Sungai Buloh Wetland Park ( $01^{\circ} 26^{\prime}$ $\mathrm{N}, 103^{\circ} \mathrm{E}$ ) (Figs. 1C, 3). The collected specimens were kept in a bottle and transferred to the Zoology Laboratory of the Biology Division of the Department of Science, Faculty of Science and Technology, Prince of Songkla University, Pattani Campus, for study. The specimens were narcotized with $7 \%$ $\mathrm{MgCl}_{2}$ for 1 hour and fixed in seawater and $10 \%$ formalin solution, before being transferred to a petridish with black wax layer. Fine needles and spines of cactus were used in dissecting the tissue. The gross morphology of their reproductive system were examined under a Stereo Microscope (Zeiss Stemi 2000-C), and photographed with attached camera (Moticam 580, 5.0 MP). 


\subsection{Light microscopy and scanning electron microscopy}

Whole mount technique such as Semichon's Acetocarmine staining technique (AFA fixative) was used for studying the morphology of the reproductive system under light microscope (Humason, 1979). For histological analysis, work was carried out on this tissue using a light microscope (LM) and a scanning electron microscope (SEM).

The dissected tissue was preserved in Bouin's fluid for 18-24 hours before being dehydrated in alcohol of $70 \%$ to $100 \%$ concentration. The tissue was next embedded in paraffin, and sliced on a microtome into $6 \mu \mathrm{m}$ serial sections, and then stained with haematoxylin and eosin for observation under an Olympus light microscope (BX 51), and photographed with attached camera (Moticam 2000).

For the study by a scanning electron microscope, the reproductive tissues of Elysia bangtawaensis, E. leucolegnote, and E. singaporensis were soaked in $2.5 \%$ glutaraldehyde in $0.1 \mathrm{M}$ Phosphate buffer saline (PBS), $\mathrm{pH} 7.8$ at $4{ }^{0} \mathrm{C}$ for 4 hours before the samples were fixed with $1 \%$ osmium tetroxide in $0.1 \mathrm{M}$ PBS, pH 7.4 at $4{ }^{0} \mathrm{C}$ for 2 hours. They were then washed off with $0.1 \mathrm{M}$ PBS $\mathrm{pH} 7.4$ at $4{ }^{0} \mathrm{C} 3$ times of 5 minutes each, and subsequently dehydrated with ethyl alcohol of 70\%, 80\%, 90\%, 95\% (twice) and $100 \%$ (twice) for 30 minutes each time, respectively. Next, the samples were dehydrated using the CriticalPoint-Drying machine. Each sample was put on a stub and coated with heavy metal before being put under LEO scanning electron microscope (series 1450 VP) and photographed.

\section{RESULTS}

Reproductive System In Elysia bangtawaensis E. leucolegnote And E. singaporensis

3.1 Overview of Reproductive System of Elysia bangtawaensis, $E$. leucolegnote and $E$. singaporensis

An obvious feature in the reproductive system of Elysia bangtawaensis and E. leucolegnote is that they have distinct male and female follicles. In addition to their normal locations, both male and female follicles can also be found among the tubules of the digestive gland. Elysia singaporensis has what is called a hermaphrodite follicle (Figs. 4-6, 7A-B). In Elysia bangtawaensis, the short oviduct connects to the central canal, and the male connects to the vas deferens. (Fig. 4) In the lumen of the central canal, cilia help move eggs forward. The short oviduct leading to the left transports endogenous eggs into the central canal to wait for exogenous sperms. It is very likely that it is in this canal that fertilization of the eggs by sperm of other individuals of E. bangtawaensis occurs. 


\subsection{Stages of spermatogenesis in Elysia spp.}

The histological study of male follicles in E. bangtawaensis and $E$. leucolegnote, and hermaphrodite follicles in E. singaporensis shows that there are cells of all stages of spermatogenesis inside the follicles. It is also observed that the egg-shaped male follicles of $E$. bangtawaensis are connected like a bunch of balloons (Fig. 9A)

The earliest development stage, or spermatogonium (sg), is found attached to the walls of the male follicles. They have big, round nuclei with loose, bluish chromatin fibers, making the nuclei transparent. Their cytoplasm is pushed to the thin, transparent layer around nuclei (Figs. 8A-C).

At the primary spermatocyte (psc) stage, the sperms are a little larger than those of the spermatogonium. The chromatin fibers become more condensed and spread almost throughout the cells, making the space between the nuclei and cytoplasm unclear. Nucleolous is not found at this stage (Figs. 8A-C).

As for the secondary spermatocyte (ssc) stage, it is difficult to find sperms because this stage is passed very quickly.

At the spermatid (st) stage, sperm cells also cluster in the lumen. They are much smaller than those of the secondary spermatocyte, and appear as darkcolored spots only since the chromatin fibers coil very tightly together. There is little or no cytoplasm (Figs. 8A-C).

In the last stage of development, spermatozoa (sz) become mature in the lumen. Their heads of rod shape and deep-blue color point towards basal lamina. Their tails which consist of middle pieces and tail pieces point towards the lumen, and look like pale pink pompoms swaying to and fro (Figs. 8A-C).

\subsection{Stages of oogenesis in Elysia spp.}

In E. bangtawaensis, the female follicles appear like a bunch of grapes (Fig. 8D). A lot of oocytes are found inside the female follicle, mostly in fully developed stage (Figs. 8E-F). The yolk forming stage (vitellogenesis) is clearly visible inside the oocyte (Fig. 8G). The female follicles of E. bangtawaensis are connected to the yellowish female duct, which is larger than the male duct, and has a thicker epithelium (Fig. 7B). The follicle sections of E. leucolegnote, was not observed in this study. In $E$. singaporensis, we found the early stage of oocytes which appeared to be near stages of sperm cell development (Fig. $8 \mathrm{C})$.

\subsection{Prostate Glands}

Prostate glands of all three species, E. bangtawaensis, $E$. leucolegnote and E. singaporensis, have ramifications, and the ramified lobe shape of prostate gland can be seen (Figs. 7A, 9A, 9C). These glands have glandular simple columnar epithelium. At certain points they have pseudostratified epithelium with dark blue nuclei of cells in basal position (Figs. 9D-E). The prostate glands branch out from the axis of the body until it reaches the parapodial margins. They are also found among the follicles. Medially, the prostate glands are on the top, but distally parts of them are under the male follicles in E. bangtawaensis and $E$. 
leucolegnote or the hermaphrodite follicle in E. singaporensis (Figs. 4-6).

\subsection{Vas deferens and Penis}

The vas deferens serves to transfer endogenous sperm to the penis. All three species have a penis without a stylet. The penis of E. bangtawaensis has a conical shape while the penis of $E$. leucolegnote has a conical shape with a narrow extension, and the penis of $E$. singaporensis is cone-shaped with a narrow tip. The tips of their penises, with their openings, point towards the base of the right rhinophore (Figs.10A-C). The cross sections of the vas deferens show the lumen is lined by a simple cuboidal epithelium. The vas deferens of $E$. leucolegnote is surrounded by a small layer of smooth muscle. The cross sections of penis in E. leucolegnote and $E$. singaporensis show that the vas deferens inside the penis has the lumen surrounded by simple squamous epithelium and smooth muscle (Figs. 11A-B).

\subsection{Nidamental Gland}

The nidamental gland is found at the center of reproductive system right anterior part of the body of Elysia bangtawaensis, E. leucolegnote and E. singaporensis. It consists of capsule gland and mucous gland, whereas the albumen gland forms a highly branched system that usually follows the digestive gland tubules. The capsule gland and mucous gland are closely connected, forming a pale ball. When observed under a stereo microscope, it looks like transparent jelly. When cut crosswise, the capsule gland reveals scattered haematoxylin stained granules (Figs.12A-C).The albumen glands are small ducts on top of two thirds of the prostate glands lengthwise (Fig. 9B). In addition, we found that the albumen gland in all three species feature ramification, especially in $E$. leucolegnote and E. singaporensis, where the glandular parts look like a bunch of grapes (Fig.12D).

\subsection{Ampulla}

The ampulla is a structure for storing endogenous sperm. We found ampullae only in E. leucolegnote and $E$. singaporensis. In E. leucolegnote there is one ampulla on each side, and $E$. singaporensis has four on each side (Figs. 5-6). This organ was not detected in E. bangtawaensis (Fig. 4). In cross section the ampulla has simple columnar epithelium with haematoxylin-stained nuclei. At certain points pseudostratified epithelium with dark blue nuclei in basal position is found. We also observed many sperm inside the ampulla (Figs. 13A-B).

\subsection{Genital receptacle}

This organ was found only in $E$. leucolegnote and E. singaporensis, and not in E. bangtawaensis. The genital receptacle is spherical in shape. In $E$. leucolegnote, genital receptacle receives the sperm straight from bursa copulatrix. The sperm are transfered to unknown duct 1 before splitting into unknown duct 2 which is connected to long oviduct into central canal. While, the other end of unknown duct 2 is entered into capsule gland (Fig. 5). Whereas, in $E$. singaporensis, this structure receives the sperm from bursa copulatrix and sperm are sent via unknown duct to central canal (Fig. 6). In cross section the genital receptacle has a simple cuboidal epithelium with haematoxylin stained nuclei. We also observed sperm or yolk mass inside this organ, and it is assumed that unused sperm and yolk mass are 
transferred to this organ for storage or resorption (Figs. 14A-B).

\subsection{Vagina aperture}

The vagina aperture is the point that all of three species in Elysia use to receive the exogenous sperm for fertilization. As, the position of vagina aperture of E. bangtawaensis is on the right ventral of parapodia and also close to the anus, whereas in E. leucolegnote and E. singaporensis have the position at the edge of the pericardium. This opening has dense stratified squamous epithelium and is close to the anus. When the sac is cut into cross sections, a simple squamous epithelium appears together with its haematoxylin-stained nucleus (Figs. 15A-C.). The results of this study are summarized in Table 1.

Table 1. Comparison Of The Reproductive Organs In Three Elysia spp.

\begin{tabular}{lccc}
\hline Characteristics & E. bangtawaensis & E. leucolegnote & E. singaporensis \\
\hline 1. Penis & $\begin{array}{l}\text { Unarmed, conical } \\
\text { shape }\end{array}$ & $\begin{array}{l}\text { Unarmed, conical } \\
\text { with narrow } \\
\text { extension }\end{array}$ & $\begin{array}{l}\text { Unarmed, cone } \\
\text { shaped with thin tip }\end{array}$ \\
\hline $\begin{array}{l}\text { 2. Reproductive } \\
\text { aperture }\end{array}$ & Triaulic & Triaulic & Triaulic \\
\hline 3. Follicle & $\begin{array}{c}\text { Separated male and } \\
\text { female follicles }\end{array}$ & $\begin{array}{c}\text { Separated male and } \\
\text { female follicles }\end{array}$ & $\begin{array}{c}\text { Mixed follicles } \\
\text { (Hermaphrodite } \\
\text { follicles) }\end{array}$ \\
\hline 4. Ampulla & Absent & One on each side & Four on each side \\
\hline 5. Albumen gland & Ramified & $\begin{array}{l}\text { Ramified, like a } \\
\text { bunch of grapes }\end{array}$ & $\begin{array}{c}\text { Ramified, like a } \\
\text { bunch of grapes }\end{array}$ \\
\hline 6. Prostate gland & Ramified & Ramified, lobe shape & Ramified, lobe shape \\
\hline 7. Nidamental gland & $\begin{array}{c}\text { Albumen gland } \\
\text { Capsule gland }\end{array}$ & $\begin{array}{c}\text { Albumen gland } \\
\text { Capsule gland } \\
\text { Mucous } \text { gland }\end{array}$ & $\begin{array}{c}\text { Albumen gland } \\
\text { Capsule gland } \\
\text { Mucous gland }\end{array}$ \\
\hline $\begin{array}{l}\text { 8. Seminal } \\
\text { receptacle }\end{array}$ & Mucous gland & - & - \\
\hline $\begin{array}{l}\text { 9. Genital } \\
\text { receptacle }\end{array}$ & Absent & Spherical shape & Spherical shape \\
\hline
\end{tabular}

\section{DISCUSSIONS}

The reproductive apertures in $E$. bangtawaensis, E. leucolegnote and E. singaporensis connect to three genital ducts, sperm duct or vas deferens, vaginal duct, and oviduct (i.e., the system is triaulic). This is similar to $E$. australis and E. timida, but different from E. chilkensis, E. trisinuata and E. maoria, which have two genital ducts, namely vas deferens and oviducal duct (see Jensen, 1992; Reid, 1964).
Generally, the nidamental glands in Opisthobranchia are composed of three glands, the albumen gland, capsule gland (membrane gland), and mucous gland, which are located adjacent to one another (Ghiselin, 1965; Rudman \& Willan, 1998; Klussman-Kolb, 2001). Our results (E. bangtawaensis, E. leucolegnote and E. singaporensis) showed that the albumen gland is not part of the so-called "nidamental gland complex", but forms a highly branched system, usually following the digestive gland tubules. This characteristic is also 
found in E. viridis and E. ornata (see Klussman-Kolb, 2001). The structure of mucous and capsule glands in $E$. bangtawaensis, E. leucolegnote and E. singaporensis is a loosely compacted mass located in the central body cavity.

The absence of a penis stylet in the genus Elysia was reviewed by Reid (1964). This was also reported by Swennen (2011) and Jensen (2015), and our examinations of E. bangtawaensis, E. leucolegnote and E. singaporensis concur. The penis of E. bangtawaensis has a conical shape, that of $E$. leucolegnote has a conical shape with narrow extension, and $E$. singaporensis has a narrow tip. The conical shape without a stylet is similar to those of other species, such as E. chlorotica, E. cauze, E. flava, E. maoria, E. chilkensis, E. timida, and E. bengalensis (see Marcus, 1980; Thompson \& Jaklin, 1988; Jensen, 1992; Swennen, 2011). Additionally, the function of the penis to transfer the sperm from one animal into a bursa copulatrix of a second animal via hypodermic injection (Gascoigne, 1974) is consistent with the report of Jensen (1986) that sperm is delivered in Elysia's unarmed penis by passing into the subepidermal tissues. Occurrences of hypodermic injection in E. maoria and $E$. timida were reported by Reid (1964) and Schmitt et al. (2007) respectively.

The lack of seminal receptacle, genital receptacle, and ampulla in $E$. bangtawaensis is similar to E. maoria, whereas the presence of two organs, the genital receptacle and ampulla, in $E$. leucolegnote and E. singaporensis is similar to E. australis (Reid, 1964; Jensen, 1992). Reid, (1964) assumed that the ampulla has an important role for storing endogenous sperm. Rudman and Willan (1998) mentioned that the vagina may lead to two sperm sacs, namely a seminal receptacle and bursa copulatrix. However, there may be only one sac in some members of some families of opisthobranchia. Based on external morphology, we found only the bursa copulatrix, but not seminal receptacle, and the histological sections that show this structure has a thin walls connected with vaginal opening and we also did not see the characteristic as a folded wall which is surrounded by a thick muscular layer (as see in seminal receptacle) (Schmekel, 1971). The role of the bursa copulatrix is to collect exogenous sperm and break down prostatic secretions. However, our results differ from the earlier report of Jensen (1990) on E. leucolegnote and Jensen \& Wells (1990) on E. australis that the seminal receptacle is the distal structure as connected with the vaginal opening but not bursa copulatrix. We assume that the genital receptacle may not be homologous to the structure called bursa copulatrix because of the different connections to other reproductive structure, including the function of genital receptacle to store discarded sperm and eggs.

Our results confirm that the follicles of $E$. bangtawaensis and $E$. leucolegnote are completely separated as female and male follicles. This characteristic is similar to that found in E. maoria and E. ornata (see Reid, 1964; Marcus \& Marcus, 1970; Jensen, 1992). In E. singaporensis however, follicles are hermaphroditic (ovotestis). This agrees with most species of Elysia such as E. flava, E.timida, E. trisinuata and E. chilkensis (see Thompson \& Jaklin, 1988; Jensen, 1992)

The ramified structure of the albumen and prostate glands are found in all Elysia (see Reid, 1964), and our result confirm this. However, in $E$. 
leucolegnote and E. singaporensis, the prostate gland is shaped like a lobe, while that of E. bangtawaensis has a branching pattern where the prostate duct run parallel and connect to the prostate gland. Albumen gland in $E$. leucolegnote and E. singaporensis is shaped like a bunch of grapes.

This study shows the presence of a genital receptacle and ampullae in $E$. leucolegnote and E. singaporensis but not in E. bangtawaensis. The similarities in morphology of the two organs in $E$. leucolegnote and E. singaporensis suggest a shared phylogenetic lineage. However, if we consider the characteristics of follicles in the three species, E. singaporensis is remarkably different from $E$. bangtawaensis and $E$. leucolegnote. Further studies, preferably with the addition of molecular analyses, will be required to confirm their phylogeny of these interesting slugs.

\section{ACKNOWLEDGEMENTS}

We would like to thank Dr. Cornelis (Kees) Swennen for suggestions, discussion, and comments as well. Furthermore, we are extremely thankful to Tan Siong Kiat from National University of Singapore for suggestions and comments. Our grateful thanks are due to research funding from Prince of Songkla University, Pattani campus, Thailand for their financial support throughout this project.

\section{REFERENCES}

Gascoigne, T. (1974). A note on some sacoglossan penial styles (Gastropoda: Opisthobranchia). Zoological Journal of the Linnean Society. 55: 53-59.
Ghiselin, M.T. (1965). Reproductive function and the phylogeny of opisthobranch gastropods. Malacologia. 3: 327-378.

Hadfield, M.G. \& Switzer-Dunlap, M. (1984). Opisthobranchs: Order Sacoglossa. In The Mollusca volume 7 Reproduction, (ED.To, pa, A.S., Verdonk, N.H. and Van Den Biggelaar, J, A.M.), pp. 238242. Academic Press, London.

Humason, G.L. (1979). Animal tissue techniques. $3^{\text {rd }}$ ed. W.H. Freeman and Company, San Francisco, California.

Jensen, K.R. (1986). Observation on copulation in two species of Elysia fro, Florida USA (Opisthobranchia, Ascoglossa). Ophelia. 25(1): 25-32. (E. patina)

Jensen, K.R. (1990). Three new species of Ascoglossa (Mollusca, Opisthobranchia) from Hong Kong, and a description of the internal anatomy of Costasiella pallida Jensen, $1985 . \quad$ In: Morton,B. (ed.), Proceedings of the Second International Marine Biological Workshop: The Marine Flora and Fauna of Hong Kong and Southern China pp. 419-432. Hong Kong University Press, Hong Kong.

Jensen, K.R. (1992). Anatomy of some indo-pacific elysiidae (opisthobranchia: sacoglossa (=Ascoglossa)). With a discussion of the generic division and phylogeny. Journal of Molluscan Studies. 58: 257-296.

Jensen, K.R. (2015). Sacoglossa (Mollusca: Gastropoda: Heterobranchia) from northern coasts of Singapore. Raffles 
Bulletin of Zoology, Supplement. 31: 226-249.

Jensen, K.R. \& Wells, F.E. (1990). Sacoglossa $\quad(=$ Ascoglossa $)$ (Mollusca, Opisthobranchia) from southern Western Australia. In:Wells, F.E.,Walker, D.I., Kirkman, H. \& Lethbridge, R.(eds.). Proceedings of the Third International Marine Biological Workshop: The Marine Flora and Fauna of Albany, Western Australia. Western Australian Museum, Perth, 1: 297-331.

Kieckbusch, D.K, Koch, M.S., Serafy, J.E., \& Anderson, W.T. (2004). Trophic linkages among primary producers and consumers in fringing mangroves of subtropical lagoons. Bulletin of Marine Science. 74(2): 271-285.

Klussman-Kolb, A. (2001). Comparative investigation of the genital systems in the Opithobranchia (Mollusca, Gastropoda) with special emphasis on the nidamental glandular system. Zoomorphology. 120: 215-235.

Marcus, E.R. \& Marcus, Ev.du B.R. (1970). Opisthobranchs from Curaçao and faunistically related regions. Stud. Fauna Curaçao other Caribbean Islands. Studies on the Fauna of Curaçao and Other Caribbean Islands. 33: 1129.

Marcus, Ev.du B.R. (1980). Review of western Atlantic Elysiidae (Opisthobranchia Ascoglossa) with a description of a new Elysia species. Bulletin of Marine Science. 30: 54-79.
Reid, J.D. (1964). The reproduction of the sacoglossan opisthobranch Elysia maoria. Proceedings of The Zoological Society of London. 143: 365-393.

Rudman, W.B. \& Willan, R.C. (1998). Opistobranchia. In: Beesley, P.L., Ross, G.J.B., and Wells, A. (Eds.), Mollusca: The southern synthesis. Part B. Fauna of Australia Volume 5 Front Cover. CSIRO Publishing, Melbourne, pp. 932936.

Schrödl, M., Jörger, K., KlussmannKolb, A. \& Wilson, N.G. (2011). Bye bye "Opisthobranchia"! A review on the contribution of mesopsammic sea slugs to euthyneuran systematics. Thalassas. 27: 101-112.

Schmekel, L. (1971). Histologie und Feinstruktur der Genitalorgane von Nudibranchiern (Gastropodoa, Euthyneura). Morphologie und Ökologie der Tiere. 69: 115-183.

Schmitt, V., Anthes, N. \& Michiels, N.K. (2007). Mating behavior in the sea slug Elysia timida (Opisthobranchia, Sacoglossa): hypodermic injection, sperm transfer and balanced reciprocity. Frontiers in Zoology. 4: 17.

Swennen, C. (1998). Two new gastropods, Elysia bangtawaensis and E. siamensis from southern Thailand (Opisthobranchia, sacoglossa, Elysiidae). Bulletin Zoölogisch Museum Universiteit van Amsterdam. 16(6): 33-39.

Swennen, C. (2011). Large mangrovedwelling Elysia species in Asia, with descriptions of two new species

(Gastropoda: 
Opisthobranchia: sacoglossa). The Raffles Bulletin of Zoology. 59(1): 29-37.

Thompson, T.E. \& Jaklin, A. (1988). Eastern Mediterranean Opisthobranchia: Elysiidae (Sacoglossa $=$ Ascoglossa). Journal of Molluscan Studies. 54: 59-69.
Wägele, H., Stemmer, K., Burghardt, I. \& Händeler, K. (2010). Two new sacoglossan sea slug species (Opisthobranchia, Gastropoda): Ercolania annelyleorum sp. Nov. (Limapontioidea) and Elysia asbecki sp. Nov. (Plakobranchoidea), with notes on anatomy, histology and biology. Zootaxa. 2676: 1-28. 

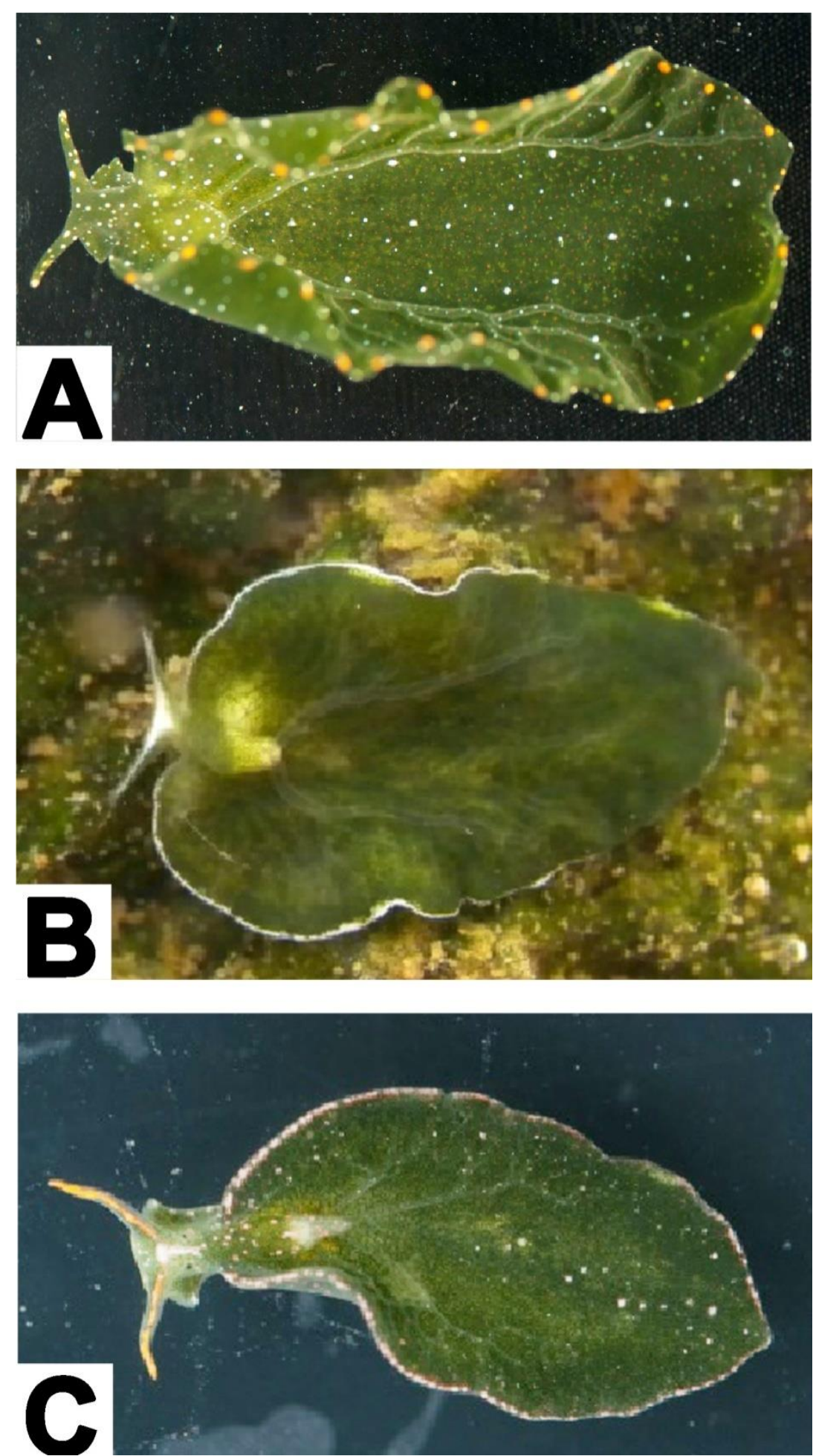

Figure 1. External morphology of Elysia bangtawaensis (A), Elysia leucolegnote (B) and Elysia singaporensis (C) (Source : Somsak Buatip) 


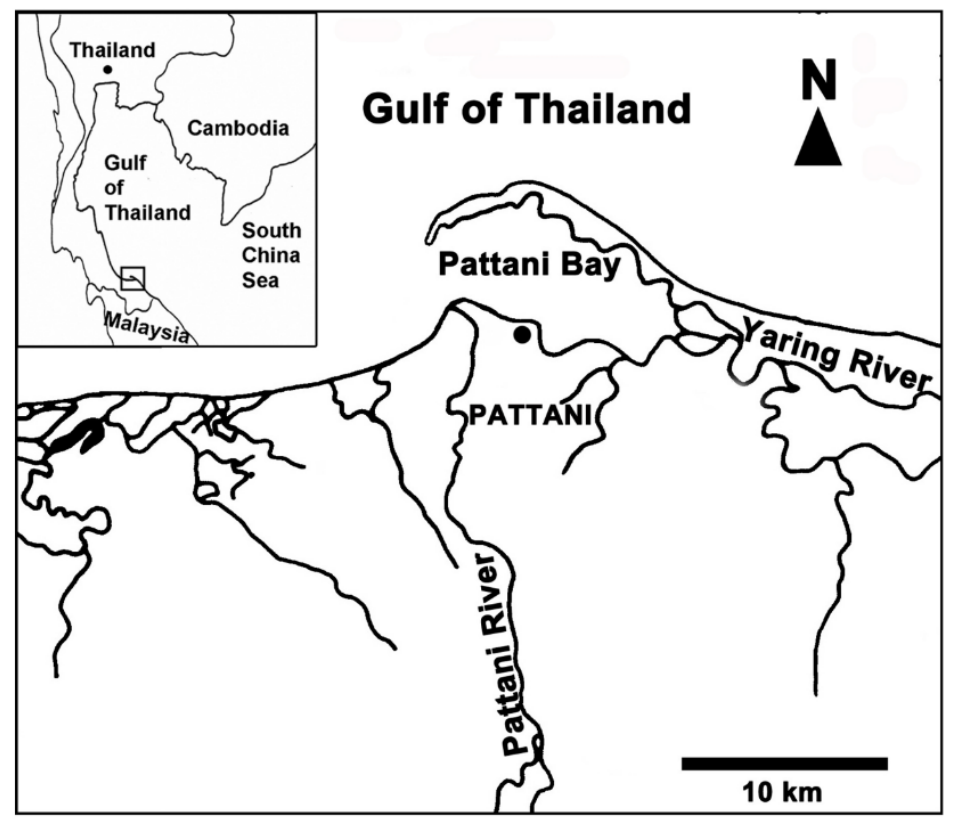

Figure 2. Study site in Pattani province, Thailand.

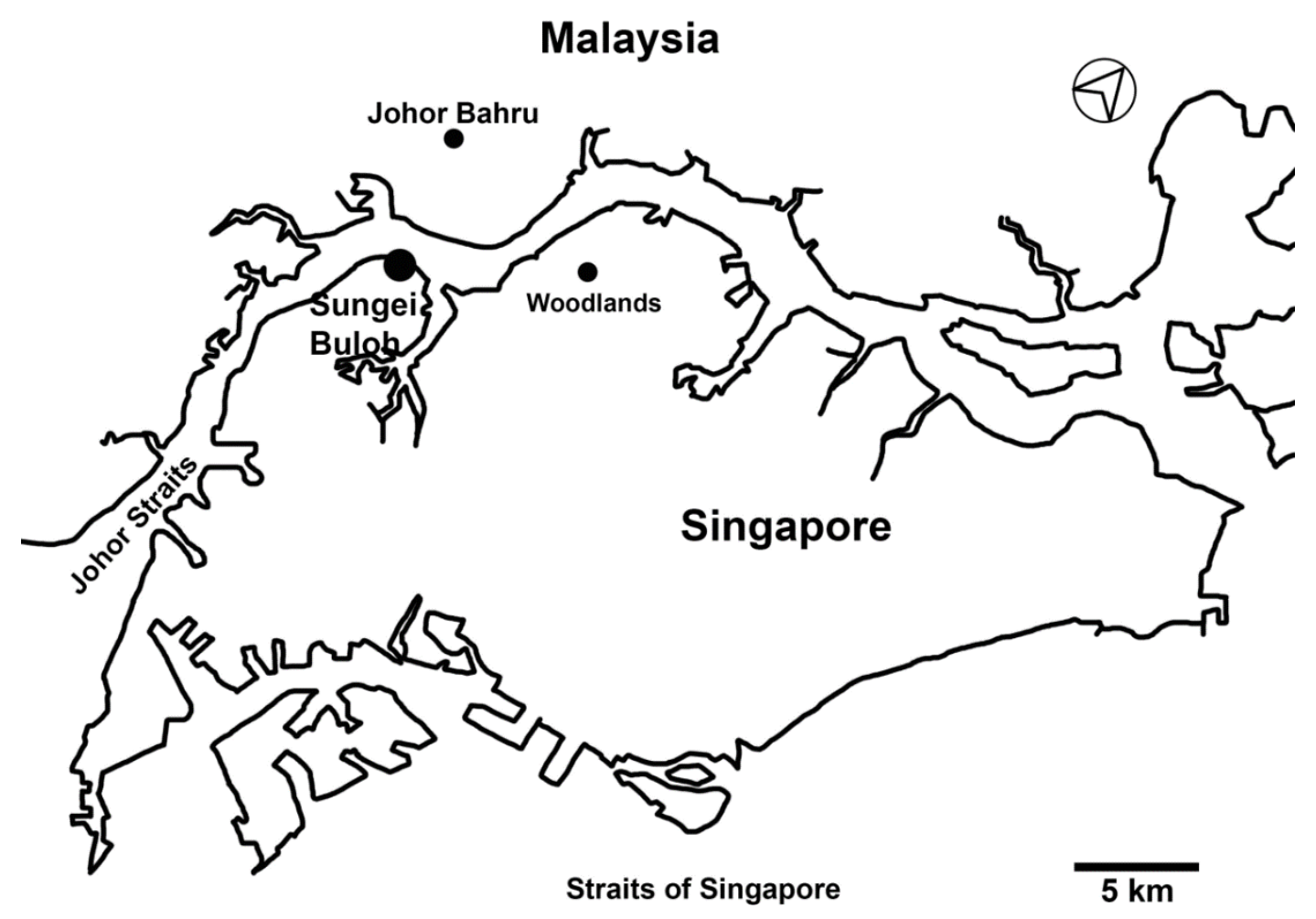

Figure 3. Study site in Western Johor Straits, Singapore. 


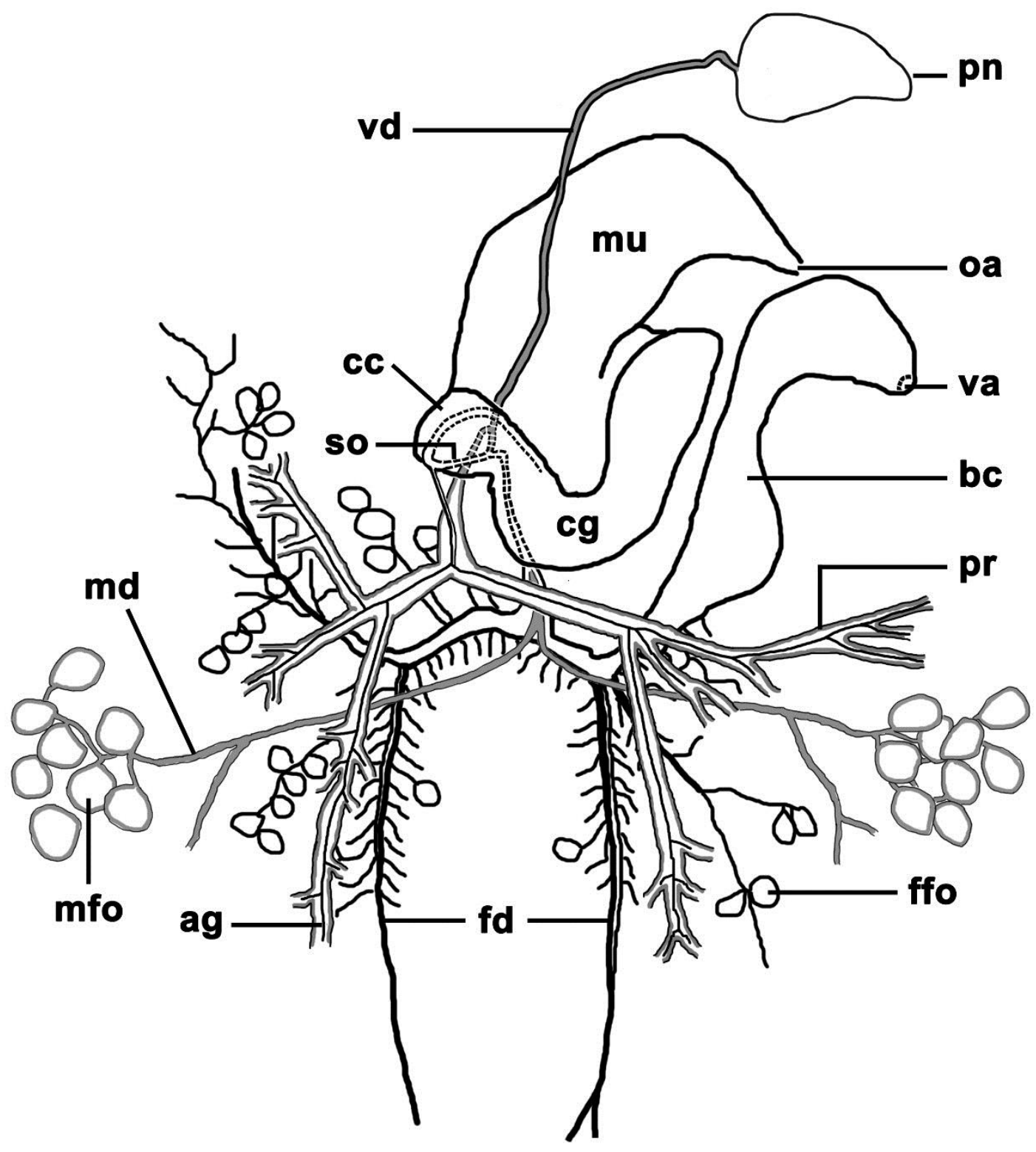

Figure 4. Diagrammatic illustration of the reproductive system of E. bangtawaensis: ag, albumen gland; bc, bursa copulatrix; cc, central canal; cg, capsule gland; fd, female ducts; ffo, female follicle; md, male duct; mfo, male follicle; mu, mucous gland; oa, oviducal aperture; pn, penis; pr, prostate gland; so, short oviduct; va, vaginal aperture; vd, vas deferens. 


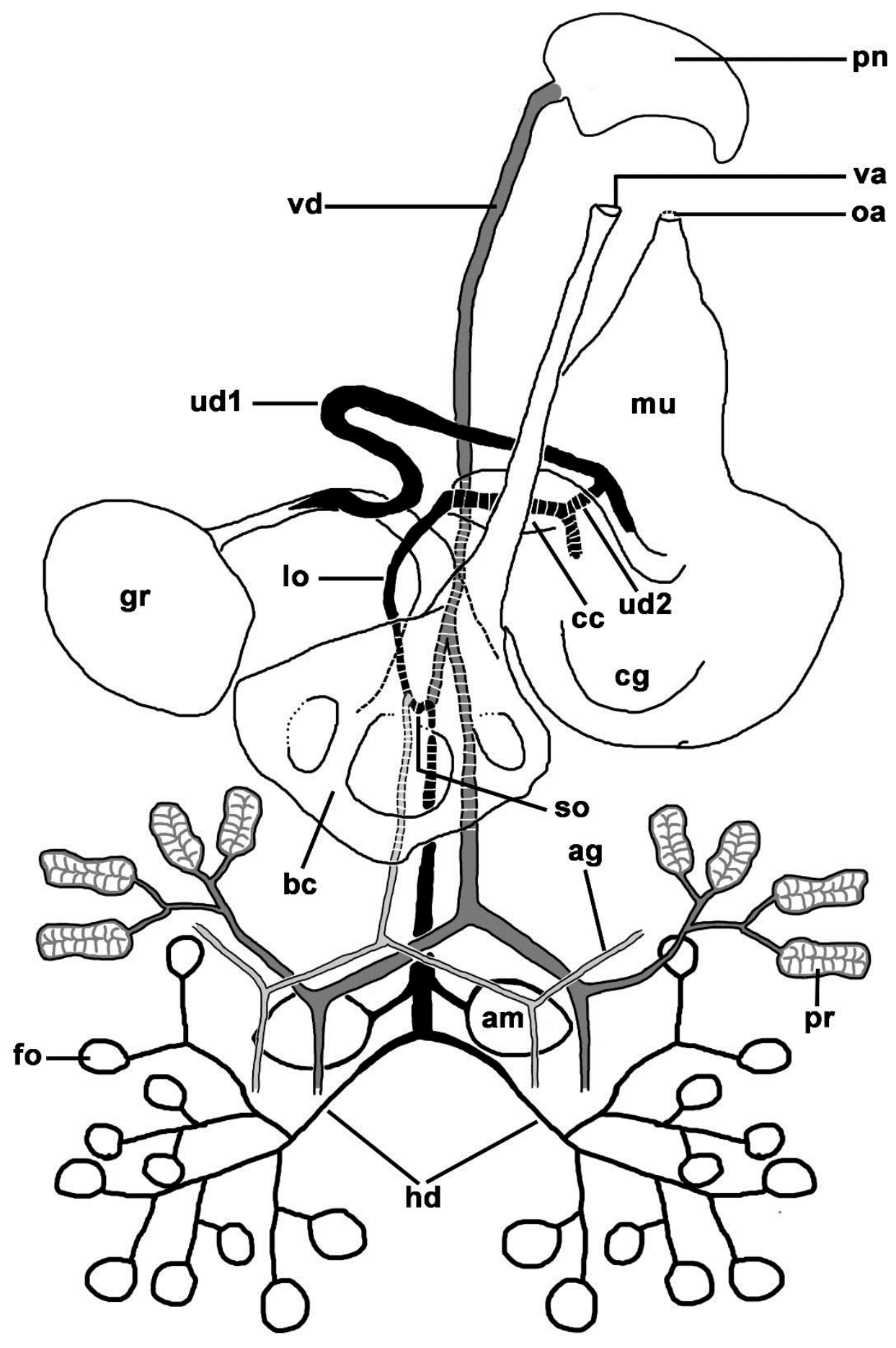

Figure 5. Diagrammatic illustration of the reproductive system of E. leucolegnote: ag, albumen gland; am, ampulla; bc, bursa copulatrix; cc, central canal; cg, capsule gland; fo, follicle; gr, genital receptacle; hd, hermaphrodite ducts; lo, long oviduct; mu, mucous gland; oa, oviducal aperture; pn, penis; pr, prostate gland; so, short oviduct; ud1, unknown duct 1; ud2, unknown duct 2; va, vaginal aperture; vd, vas deferens. 


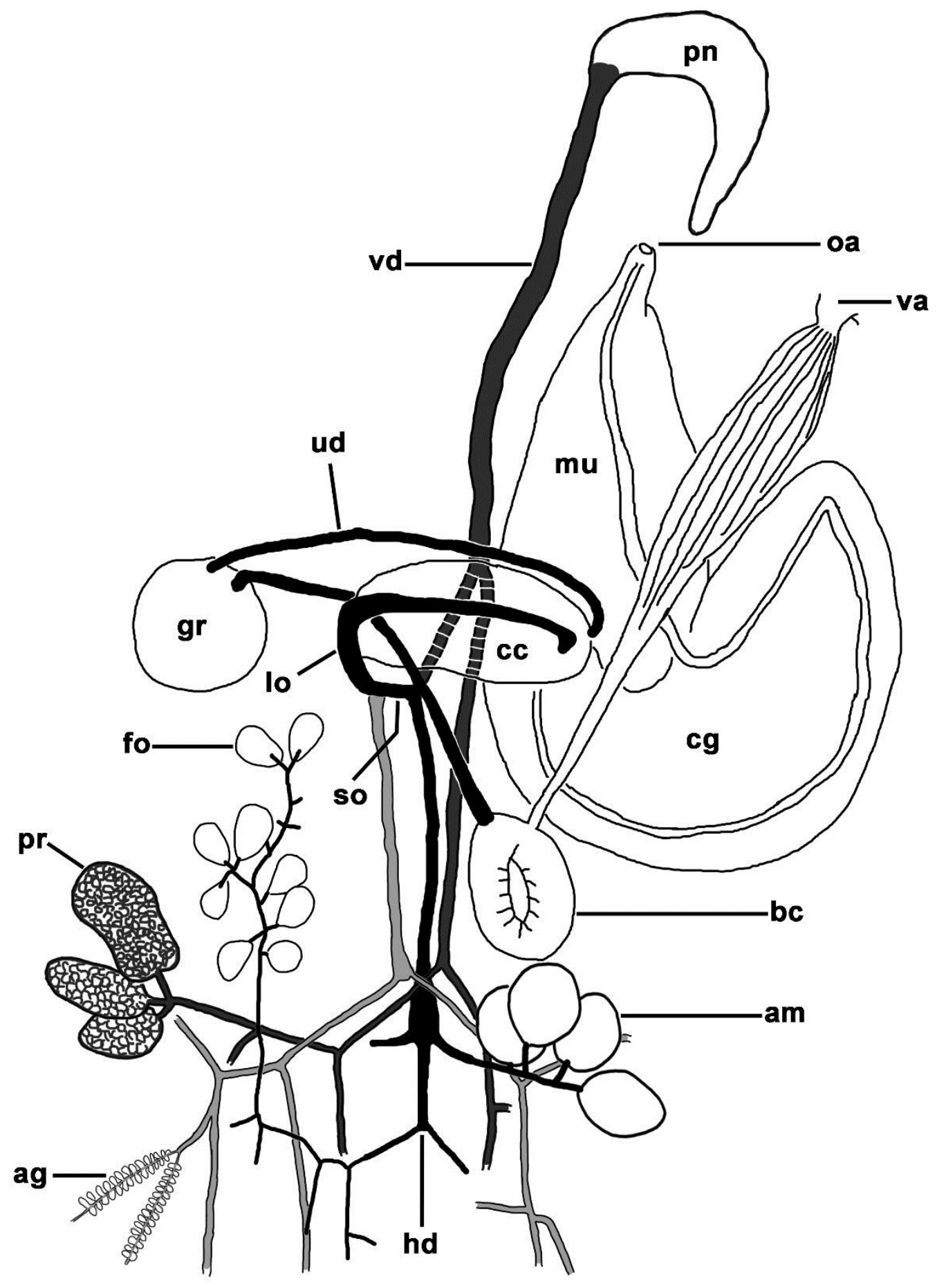

Figure 6. Diagrammatic illustration of the reproductive system of E. singaporensis: ag, albumen gland; am, ampulla; bc, bursa copulatrix; cc, central canal; cg, capsule gland; fo, follicle; gr, genital receptacle; hd, hermaphrodite duct; lo, long oviduct; mu, mucous gland; oa, oviducal aperture; pn, penis; pr, prostate gland; so, short oviduct; ud, unknown duct; va, vaginal aperture; vd, vas deferens. 

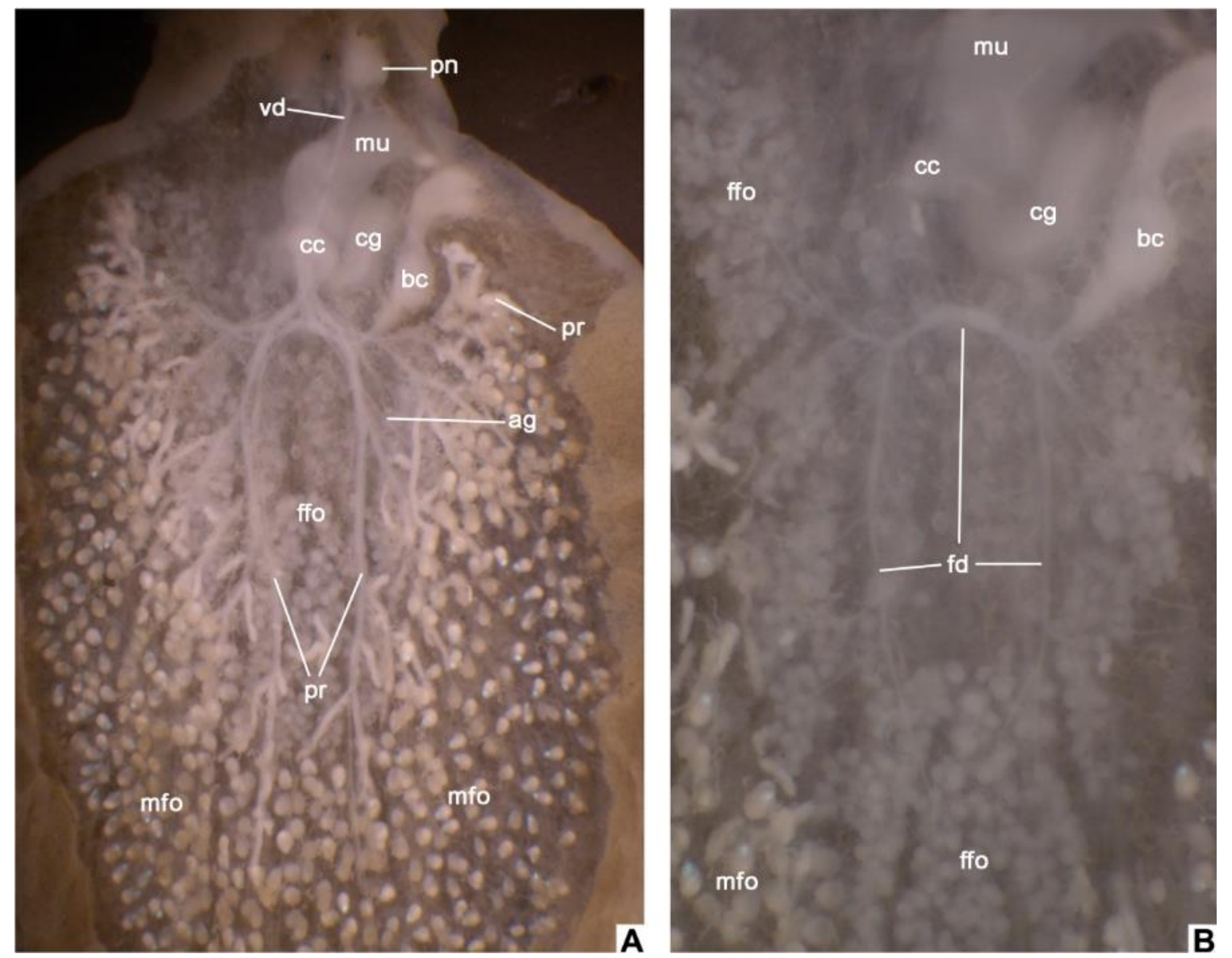

Figure 7. Photomicrographs (A-B), taken under stereomicroscope, showing the anatomy of the reproductive system in E. bangtawaensis (dorsal views):ag, albumen gland; bc, bursa copulatrix; cc, central canal; cg, capsule gland; fd, female duct; ffo, female follicle; mfo, male follicle; mu, mucous gland; pn, penis; pr, prostate gland; vd, vas deferens.
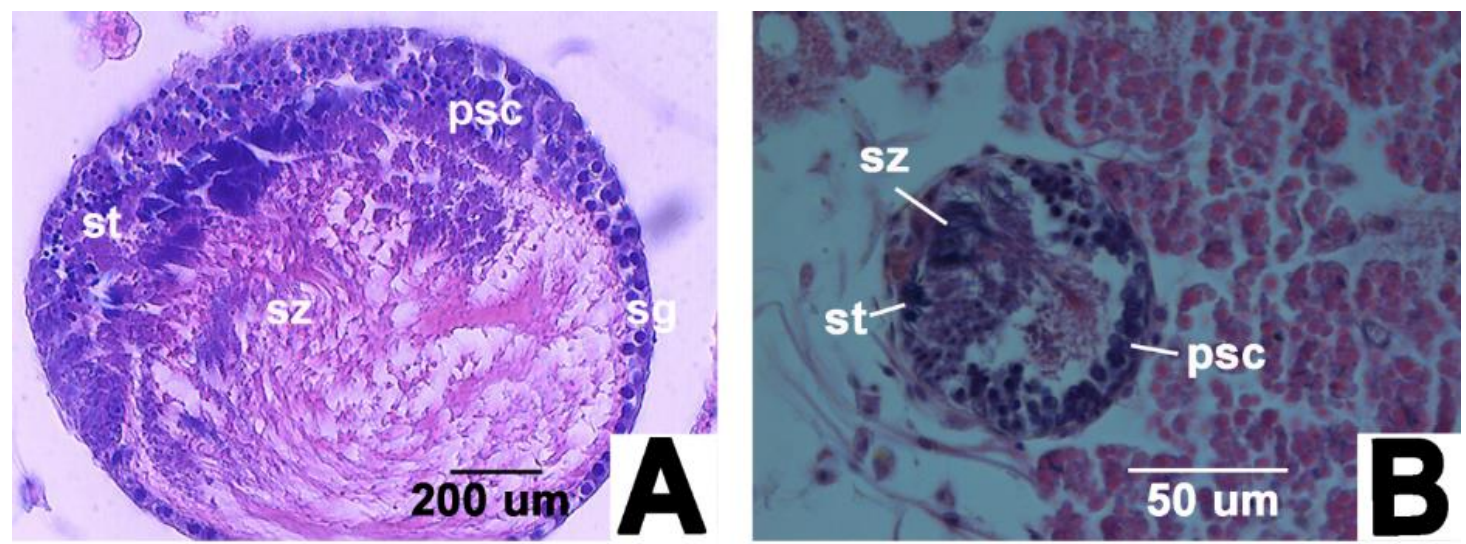

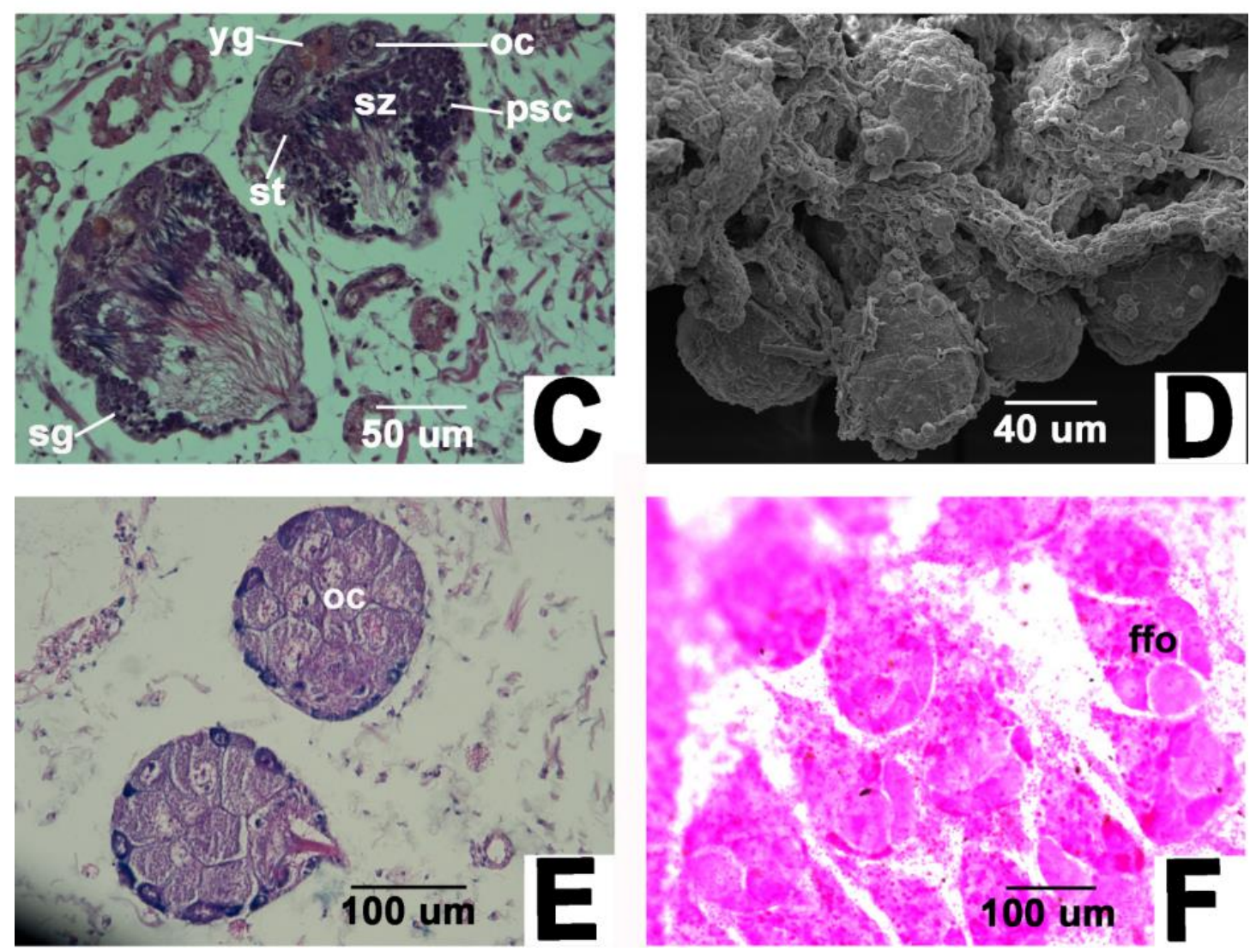

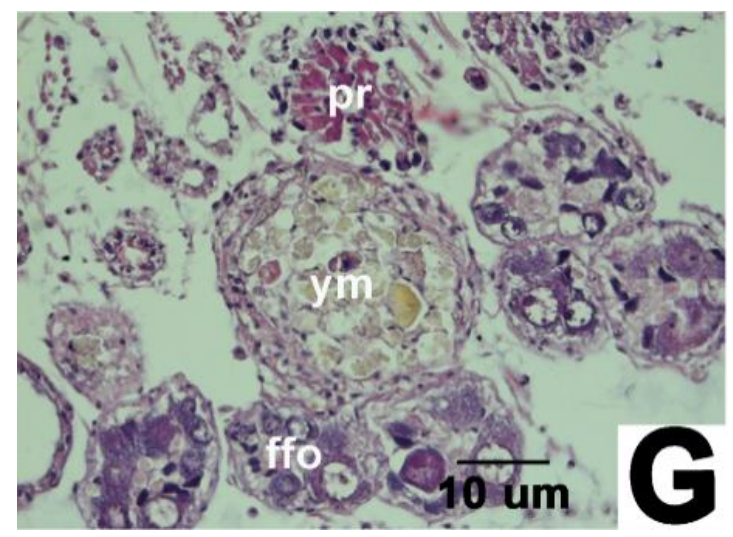

Figure 8. Photomicrographs of the follicle of Elysia spp. (A-G). A, E. bangtawaensis: Cross section of male follicle showing stages of spermatogonia, primary spermatocyte, spermatid, and spermatozoa; $\mathrm{B}$, E. leucolegnote: Cross section of male follicle showing stages of primary spermatocyte, spermatid, and spermatozoa; C, E. singaporensis: Cross section of hermaphrodite follicles showing the spermatogensis and oogensis; D, $E$. bangtawaensis: Cluster of female follicles similar to a bunch of grapes (using scanning electron microscope); E, E.bangtawaensis: Cross section of full sized oocytes with yolk-laden mature acinus; F: Female follicles of E. bangtawaensis showing many oocytes (Using AFA whole-mount technique); G, E. bangtawaensis: Cross section of female follicles showing the yellow yolk mass of the oocyte. Abbreviations: ffo, female follicle; oc, oocyte; pr, prostate gland; psc, primary spermatocyte; sg, spermatogonium; st, spermatid; sz, spermatozoa;yg, yolk gland; ym, yolk mass 

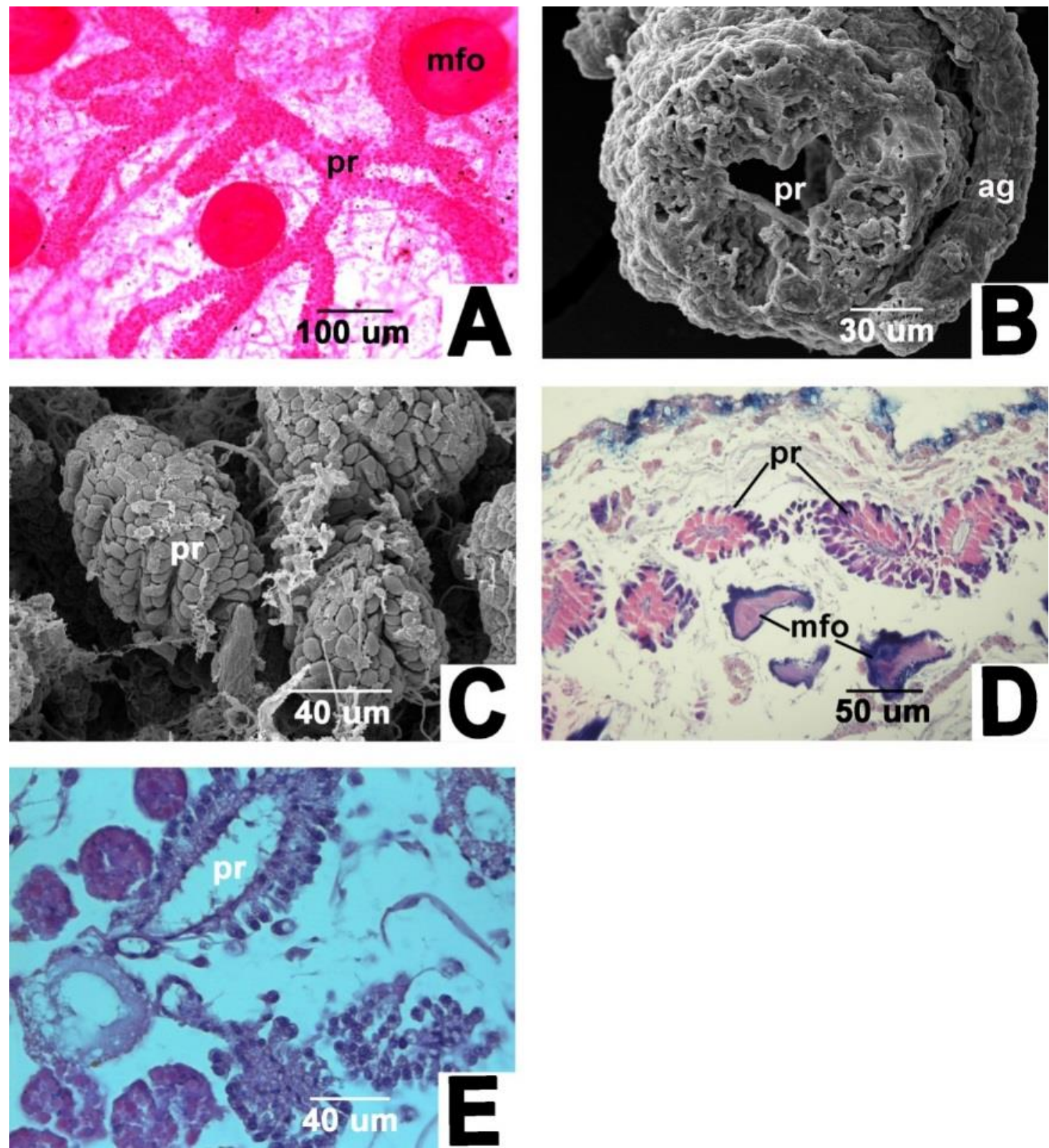

Figure 9. Photomicrographs of prostate gland of Elysia spp. showing A: Male follicle and prostate gland of E. bangtawaensis (Using AFA whole mount technique). B:

Position of albumen glands in the form of duct on prostate glands of E. bangtawaensis (Using scanning electron microscope). C: Ramified lobe shape of prostate gland of $E$. leucolegnote (Using scanning electron microscope). D: Longitudinal section of prostate glands of E. bangtawaensis, with simple columnar epithelium and pseudostratified columnar epithelium at parts. E: Cross section of prostate glands of E. leucolegnote, with simple columnar epithelium and pseudostratified columnar epithelium at parts. ag, albumen gland; mfo, male follicle; pr, prostate gland 

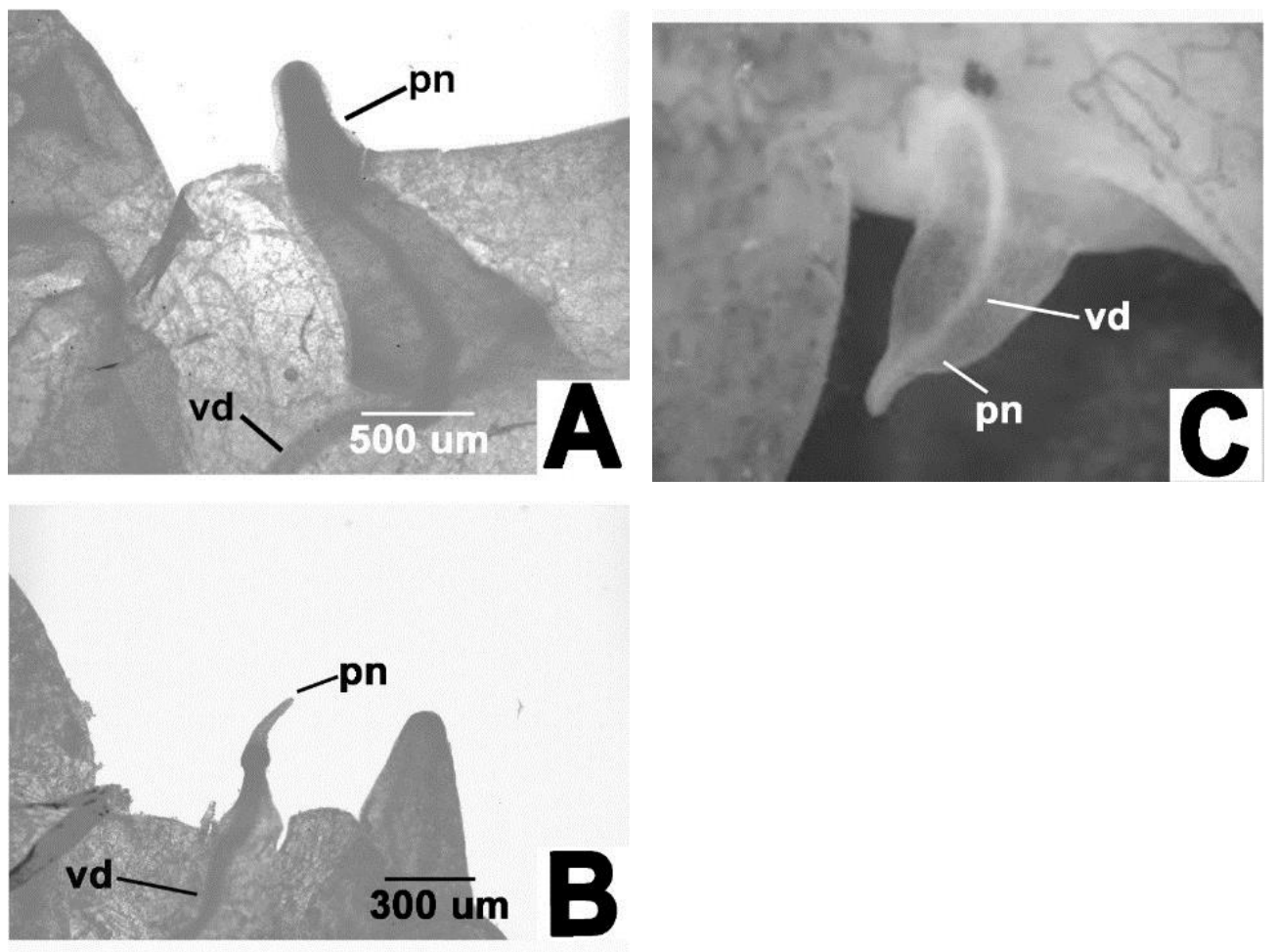

Figure 10. Photomicrographs of Penis of Elysia spp. showing A:Conical shape of penis with vas deferens of $E$. bangtawaensis (Using AFA whole mount technique). B:Conical shape of penis with narrow extension of E. leucolegnote (Using AFA whole mount technique). C:Cone shaped taper of penis with vas deferens of E. singaporensis (Using taken under stereomicroscope). pn, penis; vd, vas deferens
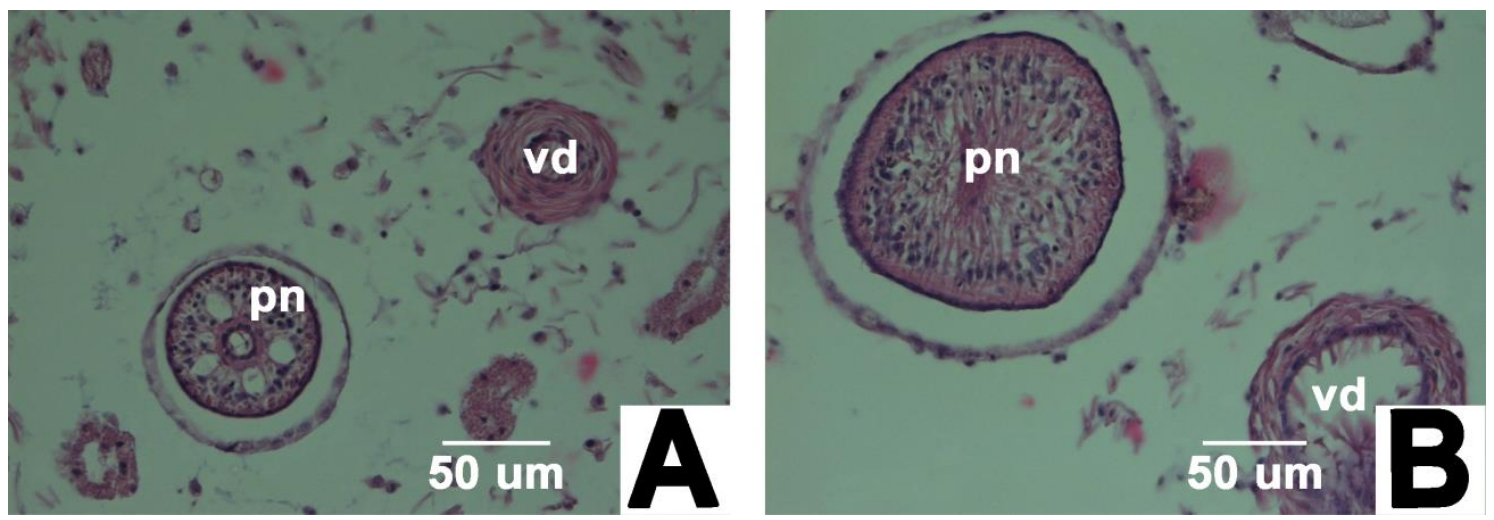

Figure 11. Photomicrographs of Penis of Elysia spp. showing A: Cross section of vas deferens and penis of E. leucolegnote. B: Cross section of vas deferens and penis of $E$. singaporensis. pn, penis; vd, vas deferens 



Figure 12. Photomicrographs of nidamental gland of Elysia spp. showing A: Cross section of mucous gland of E. bangtawaensis. B: Cross section of mucous gland and capsule gland of E. leucolegnote. C:Cross section of mucous gland and capsule gland of E. singaporensis. D:Cluster of albumen gland similar to a bunch of grapes (Using scanning electron microscope). ag, albumen gland; cg, capsule gland; mu, mucous gland; pc, pericardium 

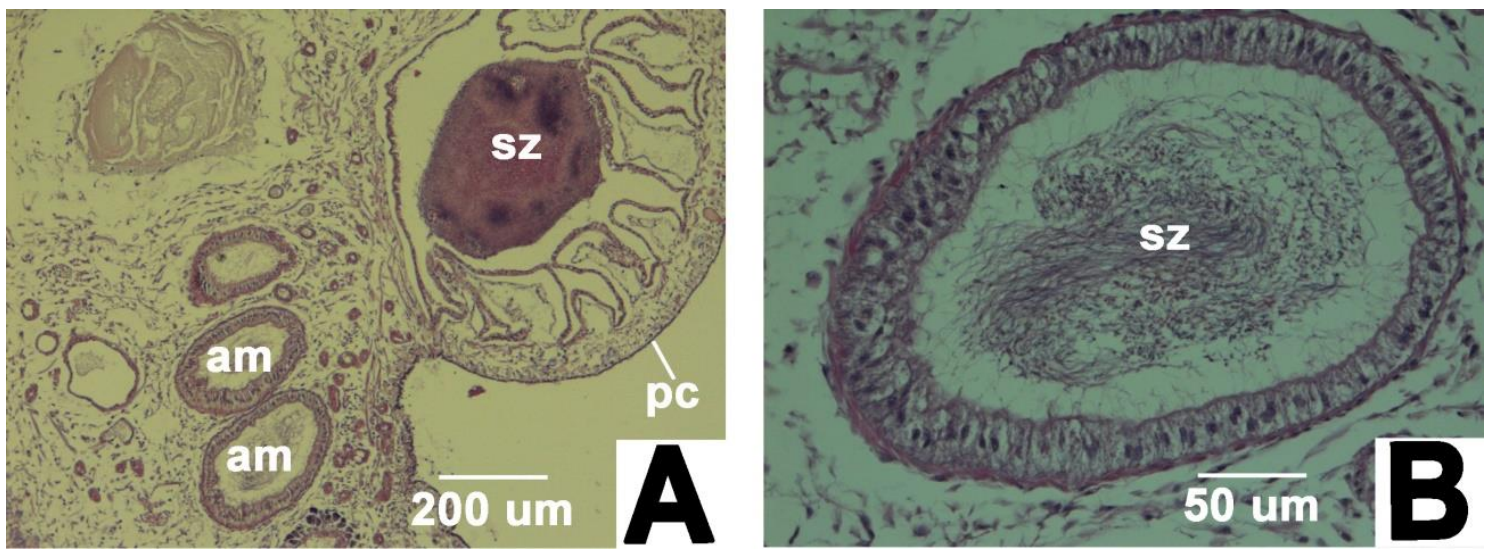

Figure 13. Photomicrographs of the cross sections of the ampulla of E. singaporensis showing many spermatozoa inside this organ (A-B). am, ampulla; pc, pericardium; sz, spermatozoa
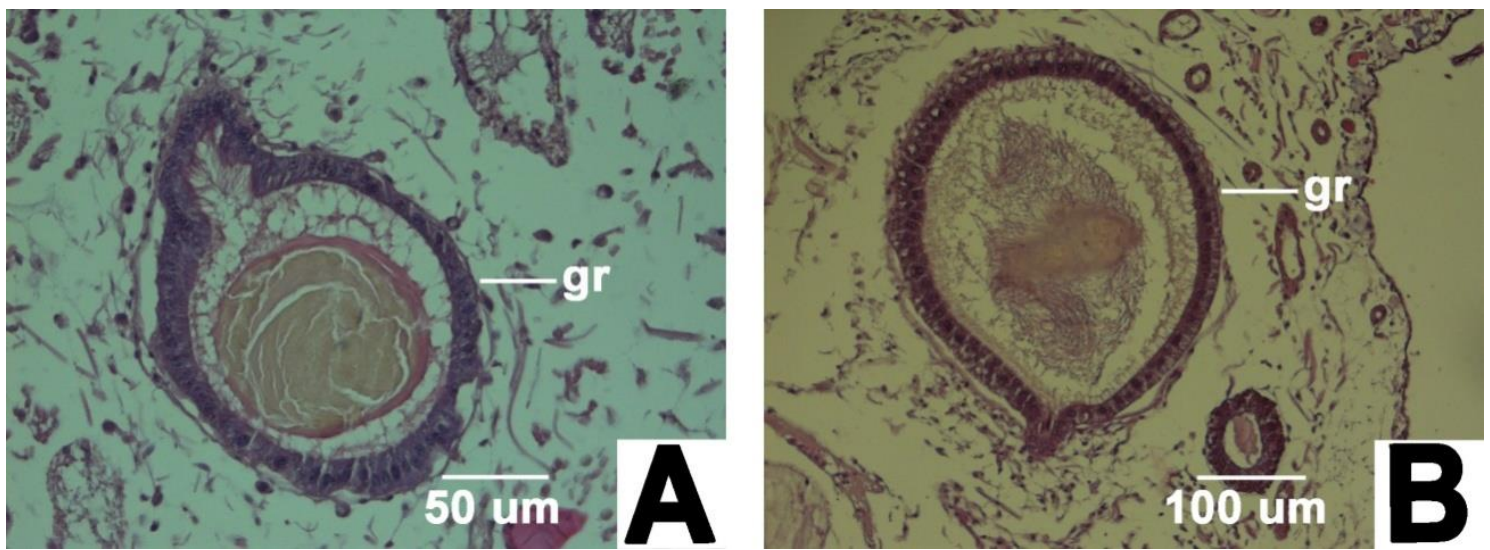

Figure 14. Photomicrographs of the cross sections of the genital receptacle of A: $E$. leucolegnote and B: E. singaporensis showing the simple cuboidal epithelium and sperm or yolk mass inside this organ. gr, genital receptacle 

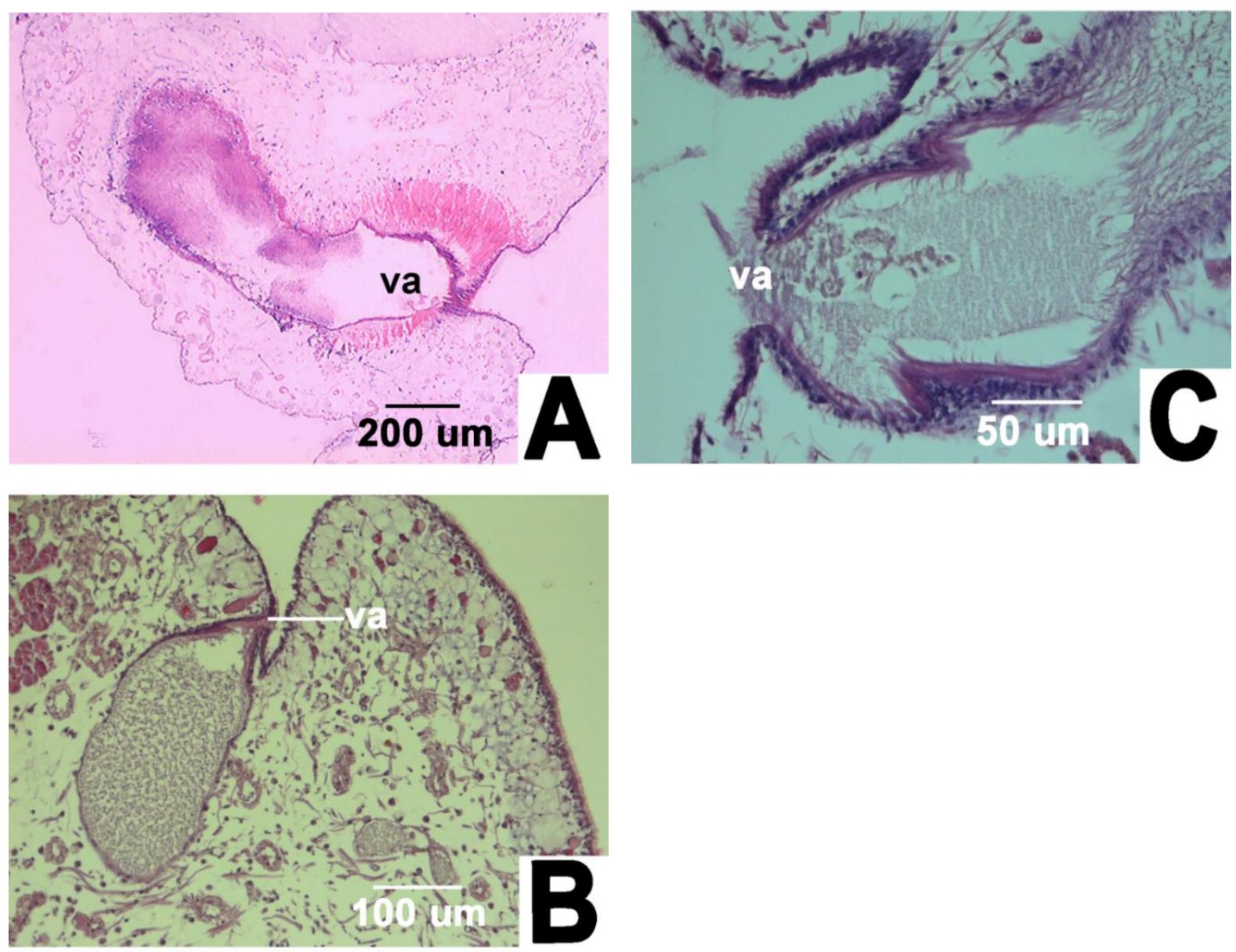

Figure 15. Photomicrographs of the cross sections of the female duct and vaginal aperture showing duct's expansion into a sac and the gradual change of the epithelium of the wall of female duct from simple squamous epithelium into stratified squamous epithelium (As seen in A: E. bangtawaensis. B: E. leucolegnote. C: E. singaporensis). va, vaginal aperture 